\title{
Wedge Resection of Lung
}

National Cancer Institute

\section{Source}

National Cancer Institute. Wedge Resection of Lung. NCI Thesaurus. Code C51625.

Surgical removal of a wedge-shaped section of lung. 